\title{
Modelling the process of technical re-equipment of the MTF with the simultaneous selection of the optimal plan for its operation on the farm
}

\author{
Arthur Alukhanyan ${ }^{1, *}$, Olga Panfilova ${ }^{1}$ \\ ${ }^{1}$ Don State Technical University, 1, sq. Gagarina, 344010, Rostov-on-Don, Russia
}

\begin{abstract}
The article deals with the issues of renovation (renewal) of the agricultural machinery and tractor fleet by developing models for developing an optimal strategy for its technical re-equipment. The optimal service life of machines in operation is considered as the most important prerequisite for the scientific management of such an update. The main criterion for the optimal strategy is the effectiveness of replacing a particular machine with a new one. The relevance of solving this problem is determined by the urgent need to plan the pace of technical re-equipment of the MTF, taking into account the presence of various economic restrictions.
\end{abstract}

\section{Introduction}

In foreign scientific papers (scientific articles, monographs, etc.), the formation of a machine-tractor fleet (MTF) of agricultural enterprises, which ensures high efficiency of the economic activity of such enterprises, is rather widely covered. In most cases, such studies are reduced to the use of economic and mathematical modelling to solve individual problems in the field of mechanization of agricultural production. So, for example, in (1), questions of minimizing the timing of operations within agricultural terms through the application of optimization procedures are considered. Several works $(2,3)$ solve the problem of developing a management system for the machine-tractor fleet of agriculture to increase the efficiency of the economic activity of enterprises in the agricultural sector of the economy. At the same time, the costs of purchasing and operating MTF machines are called the main ones in agribusiness, which are associated with a high degree of mechanization. Possible alternatives to the completion of the MTF with new agricultural machinery are emphasized: acquisition, use of leasing (4), resorting to the services of machine-technological stations. A distinctive feature of the research (5-7) is that one of the priority tasks of improving the efficiency of mechanized processes in agriculture is considered the task of increasing the daily and seasonal output of the machine and tractor fleet.

Nevertheless, in all these works the issue of the role and mechanisms of the formation of an integrated system for managing the technical re-equipment (renovation) of the machine and tractor fleet of an agricultural enterprise is not addressed.

\footnotetext{
"Corresponding author: aaalukhanyan78@mail.ru
} 


\section{Materials and Methods}

Any machine (including agricultural) is subject to physical and moral wear and tear. The physical deterioration of the machine lies in the fact that with age (operating time), on the one hand, its technical characteristics deteriorate, and on the other, operating costs increase. At the same time, physical deterioration is more determined by the increase in annual costs for repair and maintenance of the machine, rather than the deterioration of its operational properties. The moral deterioration of the machine is associated with the emergence of new models of similar equipment, characterized by better performance properties compared to old models. [1-3]

Practice shows that, as a rule, any new machine in the first year of operation is subject to various kinds of breakdowns caused by defects in the manufacturer. In subsequent periods, the operation of the machine "stabilizes", up to major repairs, after which its technical indicators are restored to some extent. Thus, the annual effect of the machine, defined as the difference between its operating time (in value terms) and all types of costs (except for depreciation), significantly depends on its age. This circumstance looks even more significant because most of the calculation methods designed to determine the optimal machine and tractor fleet use the averaged characteristics of the operating time of the machine over the years, as well as all types of operating costs and the costs of maintenance and overhauls. So, for example, the following average initial data for the Akros combine harvester were adopted:

- annual load - 160 hours;

- the annual coefficient of deductions for current repairs - 0.029 (in fractions of the book value of the machine);

- coefficient of deductions for renovation - 0.100.

Currently, there are no clear criteria for which combine harvesters belong to a particular class. However, one of the main indicators for determining class is throughput. However, it is impossible to determine the class of a combine harvester by just one indicator, which is why it is necessary to evaluate such indicators as the cleaning area, the volume of the combine hopper, the power unit power and weight (table).

Table 1. Classes and throughput of combine harvesters.

\begin{tabular}{|l|c|c|c|c|c|c|c|}
\hline $\begin{array}{l}\text { Combine harvester } \\
\text { class }\end{array}$ & 2 & 3 & 4 & 5 & 6 & 7 & 8 \\
\hline Throughput. $\mathrm{kg} / \mathrm{s}$ & up to 5 & $5-7$ & $7-9$ & $9-11$ & $11-13$ & $13-15$ & over 15 \\
\hline Cleaning area. $\mathrm{m}^{2}$ & up to 2.5 & $2.5-3.5$ & $3.5-4.3$ & $4.3-5.0$ & $5.0-5.8$ & $5.8-6.0$ & over 6.0 \\
\hline Hopper volume. $\mathrm{m}^{3}$ & up to 4 & $4-5$ & $5-8$ & $6-9$ & $8-12$ & $10-14$ & over 12 \\
\hline Engine power. HP & up to 100 & $100-210$ & $210-230$ & $230-260$ & $240-330$ & $320-460$ & over 460 \\
\hline Weight. $\mathrm{t}$ & up to 9 & $9-11$ & $11-13$ & $12-16$ & $14-18$ & $16-20$ & over 18 \\
\hline
\end{tabular}

A necessary prerequisite for the scientific management of the renewal of the machine and tractor fleet is the calculation of the optimal service life of the machines, taking into account the simultaneous influence of material and moral wear and tear, as well as the economic efficiency of replacing machines. Without these data, it is impossible to correctly plan the rate of renewal of the fleet of vehicles for various purposes to most effectively use existing and borrowed capital investment resources. There are still many unresolved issues in this area. Although a large number of methods have been proposed in domestic and foreign literature for calculating the optimal service life of machines, the vast majority of these methods, in our opinion, contain several fundamental errors and require further improvement. The existing methods for calculating the economic efficiency of replacement also require improvement, since they usually do not fully take into account changes in the 
technical and economic indicators of the operation of machines and assemblies as they age and therefore cannot ensure the correctness of the calculation results.

The experience of individual enterprises shows that the greatest efficiency from technical re-equipment is achieved where it is based on a long-term (strategic) plans and forecasts with an integrated (systemic) approach to solving this problem. An integrated approach should take into account in the long-term forecast period possible changes in the nomenclature and volume of products, as well as taking into account the latest achievements of engineering and production technology (agricultural work). Among other things, the system interaction of machines and assemblies should be taken into account. The need for an integrated approach to the technical re-equipment of agricultural production is because, as a rule, each machine in the fleet performs one or more process operations and is used in conjunction with other technologically interconnected machines, which together form a certain machine system. Replacing only one obsolete machine from a given technological system with a more productive new one may not provide proper results, since the realization of the potential advantages of a new machine may be hindered by insufficient productivity and inconsistency of other parts of this technological system. Thus, the replacement of obsolete machines should ensure the transition to a new, more efficient system of machines.

It should be emphasized that the optimal service life of the machines before retirement is not technical, but the economic category of, since if economic considerations are not taken into account, as a result of repeated repairs, the service life of any machine can be extended virtually unlimited.

As already noted above, the need to limit the service life of machines is determined by the combined effect of material and moral depreciation. As a result of material wear and tear, the technical and economic performance of machines gradually deteriorates their productivity decreases, efficiency decreases downtime in repairs and the associated costs and losses, etc. increase.

The process of reducing the technical and economic performance of machines is interrupted by mid-term and major repairs, which significantly restore the consumer properties of the machine. The process, as it were, is repeated in each repair cycle. However, which is significant, as the overall service life of the machine increases, its technical and economic indicators tend to deteriorate. At the same time, the periods between overhauls are significantly reduced, and breakdowns are increasingly occurring, which is explained by an increase in the residual wear of the machine, which cannot be eliminated by the repair. The progressive material deterioration of the machine as the service life increases significantly reduces the efficiency of its use, ultimately leading to a state where the further operation is generally unprofitable.

As already noted in several works, the annual operating time of a machine substantially depends on the age of the machine. Averaging indicators is a gross error. The operating time of the machine is determined by the actual fund of the machine's working time, which depends on the technical condition of the machine, as well as the coordinated work of other parts of the given technological chain (the effect of system interaction of machines and mechanisms). In the practice of technical and economic calculations, the assumption is made that the machine (agricultural) "goes" to the "maximum return" 5 years after its acquisition. This is due to the need to eliminate the defects laid down by the manufacturer. Further, we note that within one repair cycle, the technical characteristics of the machine tend to deteriorate (performance decreases, the likelihood of breakdowns and unscheduled repairs increases). Along with this, operating costs increase. After the next maintenance, these processes are slightly inhibited. The consumer value of the machine is restored to some extent, although unrecoverable wear leads to the fact that the general trend of 
deterioration of the technical and economic characteristics of the machine is maintained for its entire service life.

Let's try to answer the question: why does the service life of the machine depend (for example, a combine harvester)? The result of any machine is a certain consumer value, which is characterized by market conditions. For a combine harvester, this value is the harvested grain crop. Thus, the machine creates consumer value (generates income), which depends on many different factors: productivity; climatic conditions; the ratio of supply and demand on the grain market, which ultimately determines the price of its sale; various macroeconomic factors that determine the profitability (more precisely, the degree of profitability) of the production of a particular culture. Thus, the influence of a large set of purely economic indicators on the annual effect of the operation of the agricultural machine, which, in this case, is understood as the difference between the production of the machine (in value terms) and all types of operating costs and repair costs, is obvious. The optimal service life of the machines, in this case, should be determined by the ratio between these two characteristics of the machine. It turns out that the car is "aging" not only because of physical or moral wear and tear but also for some reason. This third type of obsolescence reflects the economic situation in the industry, and is therefore called "economic obsolescence".

Economic obsolescence - loss of value due to the influence of external factors. It can be caused by general economic and intra-industry changes, including a decrease in demand for a certain type of product, a decrease in supply or a deterioration in the quality of raw materials, labour, auxiliary systems, facilities and communications, as well as legal changes related to legislation, municipal regulations, zoning and administrative orders.

\section{Assessment of the prospects for the technical re-equipment of the MTF with the simultaneous selection of the optimal operating plan for machines (simplified statement of the problem)}

The simplified task of replacing the fleet of machines is being solved with the simultaneous selection of the optimal plan for the operation of the machines within the calculation period $\mathrm{T}$ (calculation horizon). The assumption is made that the productivity of workers (agricultural) machines remains unchanged over time. This does not take into account the physical wear and tear of the above machines.

In the problem, an MTF consisting of a set of J energy machines is considered. The complex of technological operations includes I operations.

The following quantities (exogenous) are considered initial in the model:

$V_{i}$ - volume (annual) of work on the $\mathrm{i}$-th operation, ha, $\mathrm{t}$.;

$\bar{t}_{j}$ - age limit for the operation of the $\mathrm{j}$-th machine (dynamic replacement programming task), years;

$w_{i j}(t)$ - daily productivity of the $\mathrm{j}$-th machine of age $\mathrm{t}(0 \leq t \leq \bar{t})$ years on the $\mathrm{i}$-th operation ha/day, t/day;

$\widetilde{w}_{i j}(0)$ - daily productivity of the purchased machine of the $\mathrm{j}$-th type of the new modification on the i-th operation;

$\tilde{c}_{j}$ - the cost of the new modification of the $\mathrm{j}$-th machine, rubles;

$N_{j}, n_{j}(t)$-respectively, the total number of $\mathrm{j}$-machines in the park and the number of cars of the $\mathrm{j}$-th type and age $\mathrm{t}$ years;

$T \mathrm{H}_{i}, T \mathrm{o}_{i}$ - the optimal agrotechnical period, respectively, of the beginning and end of the $\mathrm{i}$-th operation. 
Denote by $\lambda_{i}$ - the duration (in days) of work on the i-th operation. Then $\lambda_{i}=T \mathrm{o}_{i}-$ $T \mathrm{H}_{i}+1$.

The task is to determine the optimal number of purchased cars of all types of new modifications, as well as the optimal plan for operating cash and purchased machines. The criterion of optimization can serve as a minimum cost for the purchase of equipment. At the same time, the formed fleet of machines should ensure the performance of all operations of the technological complex in the optimal agrotechnical time frame.

Thus, managed variables are:

$\tilde{x}_{j}$ - the number of purchased machines of the j-th type of a new modification, pcs.;

$\tilde{x}_{i j}^{k}$ - the number of purchased machines of the $\mathrm{j}$-th type of the new modification used on the $\mathrm{i}$-th operation on the k-th day (agricultural term $T_{i}$ );

$n_{i j}^{k}(t)$ - number of available j-type machines (old modification) of age t years $(0 \leq t \leq \bar{t})$ used on the i-th operation on the k-th day.

Write down the terms of work:

$$
\sum_{k=T_{i}}^{T \mathrm{o}_{i}} \sum_{j=1}^{J}\left[\sum_{t=0}^{\bar{t}_{j}} n_{i j}^{k}(t) \times w_{i j}(t)+\tilde{x}_{i j}^{k}(t) \times \widetilde{w}_{i j}(0)\right] \geq V_{i},(i=1, \ldots, I) .
$$

Restrictions on managed variables are written as follows:

$$
\sum_{i} \tilde{x}_{i j}^{k}=\tilde{x}_{j}^{k} \leq \tilde{x}_{j},\left(\max _{k} \tilde{x}_{j}^{k}=\tilde{x}_{j}\right),
$$

where $\tilde{x}_{j}^{k}$ - the number of purchased machines of the j-th type of a new sample used on the $\mathrm{k}$-th day.

The condition, written in brackets, indicates that the number of purchased machines of each type should satisfy the maximum daily need for them.

Also have:

$$
\begin{gathered}
\sum_{i} n_{i j}^{k}(t)=n_{j}^{k}(t) \leq n_{j}(t),\left[\max _{k} n_{j}^{k}(t)=n_{j}(t)\right], \\
\sum_{t} n_{j}^{k}(t)=n_{j}^{k} \leq n_{j}=\sum_{t} n_{j}(t),
\end{gathered}
$$

where $n_{j}^{k}(t)$ - the number of $\mathrm{j}$-th machines of age $\mathrm{t}$ years occupied on the $\mathrm{k}$-th day; $n_{j}^{k}$ number of $\mathrm{j}$-machines used on the k-th day.

The objective function (optimized criterion) is written in the form:

$$
f=\sum_{j} \tilde{x}_{j} \times \tilde{c}_{j} \rightarrow \min .
$$

Problem (1) - (5) - linear programming problem (LPP).

With this formulation of the problem, it is assumed that only those machines whose age exceeds the maximum allowable for abandonment are written off. Another statement of this problem is also possible. Now a machine of any age can be replaced (sold on the side). This statement of the problem introduces an additional controlled variable $y_{j}(t)$ - the number of $\mathrm{j}$-machines of age $t$ years, sold on the side at their residual (liquidation) value $a_{j}(t)$.

The number of cars (from the old stock) of each type and age remaining in operation in the calculation period will be calculated using the formula

$$
n_{j}(t)-y_{j}(t),(j=1, \ldots, J ; 0 \leq t \leq \bar{t}) .
$$

In the new statement of the problem, constraints (1), (2) will remain unchanged, and constraints (3), (4) and objective function (5) will undergo some changes. So, constraints (3), (4) in the new problem are written as follows: 


$$
\begin{aligned}
\sum_{i} n_{i j}^{k}(t)= & n_{j}^{k}(t) \leq n_{j}(t)-y_{j}(t),\left(\max _{k} n_{j}^{k}(t)=n_{j}(t)-y_{j}(t)\right) \\
& \sum_{t} n_{j}^{k}(t)=n_{j}^{k} \leq n_{j}=\sum_{t}\left(n_{j}(t)-y_{j}(t)\right)
\end{aligned}
$$

It seems natural to impose the following restriction on a new controlled variable

$$
y_{j}(t) \leq n_{j}(t), t \leq \bar{t}_{j}
$$

The objective function is written in the form:

$$
f=\sum_{j}\left[\tilde{x}_{j} \times \tilde{c}_{j}-\sum_{t \leq \bar{t}_{j}} y_{j}(t) \times a_{j}(t)\right] \rightarrow \min .
$$

Problem (1), (2), (6) - (9) is also a linear programming problem and is solved by the simplex method.

\section{A dynamic model of the perspective replacement of the MTF (system approach)}

In the presented model, on the horizon of calculating $M$ years, the best strategy for the technical re-equipment of MTF (buying new equipment and selling (disposing) of old) is determined with the simultaneous selection of the optimal plan for operating available and purchased machines, which is necessary to take into account the effect of "system interaction" of individual machines. The situation of a "step-by-step" (rather than instantaneous) updating of the fleet of machines was observed in compliance with all the requirements for the performance of work in the right amount and the optimal agronomic terms, as well as the financing conditions in each year.

All source (input) information for the model can be divided into two groups of data: data on the fleet of machines and data on the technological process. [8, 12-14]

The following managed variables can be distinguished in the model:

$\tilde{x}_{j}(m)$ - number of new j-type machines purchased in the $\mathrm{m}$-th year, pcs.;

$\tilde{x}_{i j}^{k}(m)$ - the number of purchased machines of the $\mathrm{j}$-th type of the new modification used on the i-th operation on the k-th day (agricultural term $T_{i}(m)$ );

$y_{j}(m, t)$ - the number of $\mathrm{j}$-machines of age $\mathrm{t}$ years, sold to the side in the $\mathrm{m}$-th year at their residual (liquidation) value $a_{j}(m, t)$;

$n_{i j}^{k}(m, t)$ - the number of machines of the $\mathrm{j}$-th type (old modification) of age $\mathrm{t}$ years remaining in operation in the $\mathrm{m}$-th year used on the $\mathrm{i}$-th operation on the $\mathrm{k}$-th day.

Several restrictions are imposed on the controlled variables, due to the need to perform all the work of a given technological cycle in the right amount and at the optimal agrotechnical terms, as well as a priori restrictions on the number of machines in the fleet.

Terms of work:

$$
\begin{gathered}
\sum_{k=T \mathrm{H}(m)_{i}}^{T \mathrm{o}(m)_{i}} \sum_{j=1}^{J}\left[\sum_{t=0}^{\bar{t}_{j}} n_{i j}^{k}(t, m) \times w_{i j}(t)+\sum_{t=0, r=0}^{m-1, m} \tilde{x}_{i j}^{k}(t, m-r) \times \widetilde{w}_{i j}(t)\right] \geq \\
V_{i}(m),(i=1, \ldots, I ; m=1, \ldots, M) .
\end{gathered}
$$

As can be seen from (10), machines located beyond the depreciation period $\left(t_{j} \geq \bar{t}_{j}\right)$ are not taken into account when planning work (such an assumption is quite acceptable for a simplified model). This is due, first of all, to the fact that they spent their resources and, under the annual norms of deductions for renovation, completely transferred their value to the cost of the finished product. In practice, we are everywhere (in almost every household) 
faced with cases of using equipment that is physically and morally obsolete. As a rule, this is due to a lack of funds for the technical re-equipment of enterprises.

When planning a schedule for the use of newly modified cars in this m-th year, we must consider, in addition to the cars purchased in year $\mathrm{m}$, those that were purchased earlier (in the first m-1 steps).

The need to introduce an additional index $m$ in the annual volume of work on the $i$-th operation is dictated by purely practical considerations: it is assumed that the structure of the sown area changes over time. It also takes into account the possibility of changing the optimal start and end dates, which is associated with the variability of agrotechnical and climatic conditions.

Constraints (priori) on managed variables:

$$
\begin{gathered}
\sum_{i} \tilde{x}_{i j}^{k}(m)=\tilde{x}_{j}^{k}(m) \leq \tilde{x}_{j}(m),\left[\max _{k} \tilde{x}_{j}^{k}(m)=\tilde{x}_{j}(m)\right], \\
\sum_{i} n_{i j}^{k}(t, m)=n_{j}^{k}(t, m) \leq n_{j}(t, m),\left[\max _{k} n_{j}^{k}(t, m)=n_{j}(t, m)\right], \\
\sum_{t} n_{j}^{k}(t, m)=n_{j}^{k}(m) \leq n_{j}(m)=\sum_{t} n_{j}(t, m),
\end{gathered}
$$

where $\tilde{x}_{j}^{k}(m)$ - the number of cars of the j-type of a new type purchased in the m-th year, used on the k-th day; $n_{j}(t, m)$ - the number of machines of the j-th type of age $t$ years remaining in operation in the m-th year; $n_{j}^{k}(t, m)$ - the number of cash $\mathrm{j}$-th machines of age $\mathrm{t}$ years occupied on the k-th day of the $\mathrm{m}$-th year; $n_{j}^{k}(m)$ - the number of cash $\mathrm{j}$-th machines used on the k-th day of the m-th year.

The value of $n_{j}(t, m)$ will be calculated as follows:

$$
n_{j}(t, m)=N_{j}(t-m+1)-\sum_{t=t-m+1, m=1}^{t, m} y_{j}(t, m) .
$$

In accordance with (14), for the first and second step (year), the value $n_{j}(t, m)$ is equal to

$$
\begin{gathered}
n_{j}(t, 1)=N_{j}(t)-y_{j}(t, 1), \\
n_{j}(t, 2)=N_{j}(t-1)-y_{j}(t-1,1)-y_{j}(t, 2) .
\end{gathered}
$$

The objective function is the reduced cost and loss function (RCLF) for the purchase of the necessary equipment, minus the money returned as a result of the disposal (write-off) of the machines at their residual value, as well as the operation of the machine and tractor fleet over the entire period of the calculation horizon $\mathrm{M}$.

$$
\begin{gathered}
f=\sum_{m}\left\{\sum_{j}\left[\tilde{x}_{j}(m) \times \tilde{c}_{j}(m)-\sum_{t \leq \bar{t}_{j}} y_{j}(t, m) \times a_{j}(t, m)\right]+S_{e}(m)\right\} \times \\
(1+q)^{-m} \rightarrow \min ,
\end{gathered}
$$

$\tilde{c}_{j}(m)$ - the predicted value of the machine of the $\mathrm{j}$-th type of a new sample in the m-th year; $(1+q)^{-m}$ - coefficient of discounting costs to the initial point in time; $S_{e}(m)$ - total operating costs for servicing the fleet in the $m$-th year.

In (15), it is assumed that only those machines whose age does not exceed their standard depreciation period are written off at the residual value $\left(t \leq \bar{t}_{j}\right)$. Machines older than the norm are subject to disposal.

The value of $S_{e}(m)$ should include the operational costs of servicing machines purchased in the current period (in year $\mathrm{m}$ ); machines that were purchased earlier (for previous years of the billing period) and all available machines (old modifications) located 
in the park at step $\mathrm{m}$ of the calculation period. Based on this, the value of the total operating costs for servicing the fleet in the $\mathrm{m}$-th year will be calculated as (16):

$$
S_{e}(m)=\tilde{x}_{j}(m) \times \tilde{s}_{j}(0)+\sum_{r=1}^{m-1} \tilde{x}_{j}(r) \times \tilde{s}_{j}(r, m)+n_{j}(t, m) \times s_{j}(t, m),
$$

where $\tilde{s}_{j}(r, m)$ - annual operating costs in the $\mathrm{m}$-th year of the machines of the $\mathrm{j}$-th type of a new model, in operation $r$ years; $s_{j}(t, m)$ - annual operating costs in the $\mathrm{m}$-th year of the $\mathrm{j}$ type machines of the old model, in operation for $t$ years.

The enterprise does not have an unlimited amount of money that can be spent in the current period on the technical re-equipment of the fleet. In this regard, there is a need for additional conditions (17) that limit the annual cost of funds for the purchase of equipment.

$$
\sum_{j}\left[\tilde{x}_{j}(m) \times \tilde{c}_{j}(m)-\sum_{t \leq \bar{t}_{j}} y_{j}(t, m) \times a_{j}(t, m)\right] \leq A(m),(m=1, \ldots, M),
$$

where $A(m)$ - the amount of funds available to the enterprise in the m-th year.

\section{Results of scientific research}

As the results of scientific research, several points can be singled out, one way or another, which are a prerequisite for the scientific management of the renovation of the MTF of agricultural enterprises.

Firstly, the result consists in substantiating the hypothesis about the direct dependence of the effective strategy of replacing machines in operation on the optimal terms of their service, which is reflected in linear and dynamic programming models. Secondly, an economic mechanism for controlling the process of technical re-equipment of the MTF of agricultural enterprises based on the introduction of a system of economic and mathematical models that allows for a phased solution to this problem is proposed. Thirdly, as the main restrictive inequalities of the LPP, we propose the conditions for performing all the work of a complex of technological operations in optimal agricultural terms, as well as restrictions on controlled variables. At the same time, the minimum cost for the purchase of equipment is considered as a criterion function. Fourth, the proposed dynamic model of the perspective replacement of the MTF takes into account the systematic interaction of machines and mechanisms when finding the optimal strategy for the technical re-equipment of the park, taking into account the existing restrictions on the financing of activities in each period.

Also of scientific interest is the consideration of the reduced cost and loss function as a criterial function of a dynamic model that takes into account, among other things, the funds received from the disposal of machines at the residual value. [15]

\section{Conclusion}

The process of technical re-equipment of the agro-industrial complex is a multi-factor systemic process, which should be modelled based on the development of several interconnected models designed for a phased solution of the problem. The need to minimize the exogenous parameters of the model and the transition from them to the endogenous ones, determined based on solving optimization problems, is obvious.

Further work should be focused on assessing the adequacy of the models presented to the processes taking place in real households and the corresponding adjustment of models. Model examples should be developed, general recommendations for the technical reequipment of agricultural producers in the Russian market developed. 


\section{References}

1. H. Seyyedhasani, J.S. Dvorak, Biosystems Engineering 169, 1 (2018)

2. C.G. Sorensen, D.D. Bochtis, Biosystems Engineering 105, 41 (2010)

3. A. Sopegno, A. Calvo, R. Berruto, P. Busato, D. Bocthis, Computers and Electronics in Agriculture 130, 158 (2016)

4. N.G. Vovchenko, A.A. Alukhanyan, L.Y. Andreeva, G.A. Buryakov, European Research Studies Journal 21, 3 (2018)

5. S. Shepelev, V. Shepelev, Z. Almetova, Procedia Engineering 150, 1258 (2016)

6. D. Bochtis, C.G. Sorensen, D. Kateris, Operations Management in Agriculture 117 (2019)

7. D.D. Bochtis, C.G. Sorensen, P. Busato, Biosystems Engineering 126, 69 (2014)

8. G. Smirnova, R. Sabitov, B. Morozov, S. Sabitov, N. Elizarova, IFAC-PapersOnline 48, 1230 (2015)

9. M. Karunarathna, C. Wilson, Journal of Forest Economics 29, 38 (2017)

10. P. Luukka, M. Collan, Insurance: Mathematics and Economics 65, 22 (2015)

11. Chi-Chuan Lee, Chien-Chiang Lee, Yan-Yu Chiou, Journal of International Financial Markets, Institutions and Money 51, 155 (2017)

12. G. Reina, A. Milella, R. Galati, Biosystems Engineering 162, 124 (2017)

13. Y. Hu, Y. Liu, Z. Wang, J. Wen, J. Lu, Biosystems Engineering 190, 201 (2020)

14. R.C. Tieppo, T.L. Romanelli, M. Milan, C.G. Sorensen, D. Bochtis, Computers and Electronics in Agriculture 156, 282 (2019)

15. A. Vafador, M. Tolouei-Rad, K. Hayward, K. Abhary, Journal of Manufacturing Systems 39, 53 (2016) 